\title{
PERANCANGAN MESIN PENGGILING BUMBU PECEL MENGGUNAKAN PENGGERAK MOTOR LISTRIK DENGAN METODE REVERSE ENGINEERING
}

\author{
Djoko Hari Praswanto $^{1 *}$, Soeparno Djiwo², Eko Yohanes Setyawan ${ }^{3}$ \\ 1,2,3 Fakultas Teknologi Industri Institut Teknologi Nasional Malang \\ *Email Korespondensi : djoko@lecturer.itn.ac.id
}

\begin{abstract}
ABSTRAK
Sambel Pecel merupakan makanan khas Jawa Timur khususnya daerah Blitar, Kediri dan Tulungagung. Prospek wirausaha sambel pecel ini sangat menguntungkan dan berkelanjutan, karena makanan jenis ini banyak dikonsumsi oleh masyarakat jawa timur dan menjadi pusat oleh - oleh bagi masyarakat pendatang. Produksi sambel pecel sekarang ini sudah mulai menyebar ditempat - tempat lain didaerah jawa timur, seperti daerah Pasuruan khususnya kecamatan Purwosari. Pengusaha sambel pecel cap "mawar" di Purwosari ini merupakan resep turunan dari keluarga yang berasal dari Blitar. Selama proses produksinya ditemukan beberapa kekurangan yang tidak mengikuti standar Good Manufacturing Practice (GMP) sehingga pada saat di uji laboratorium kesehatan masih belum lolos uji. Setelah dilakukan survei ditempat produksi terdapat salah satu proses yang tidak mengikuti standar GMP dalam produksi yaitu proses penggilingan kacang. oleh karena itu dalam kegiatan pengabdian masyarakat, tim akan mengkonsep mesin grinding serba guna untuk digunakan sebagai penggilingan kacang. Dari hasil kegiatan yang telah dilakukan, mesin penggiling sambel pecel dengan kapasitas alat 166,67 gram/menit menggunakan motor listrik 1 HP sebagai penggerak dapat digunakan mitra sebagai alat penggiling sambel pecel dengan mudah. Dengan adanya mesin penggiling ini, produksi mitra higienitas produk terjaga dan dapat meminimalisir biaya produksi sehingga keuntungan mitra meningkat.
\end{abstract}

Kata Kunci : Mesin Grinding Serba Guna, Produksi Makanan, Sambel Pecel, Standar GMP

\section{ABSTRACT}

Sambel Pecel is a typical food of East Java, especially in the Blitar, Kediri and Tulungagung regions. The prospect of Pecel Sambel entrepreneurship is very profitable and sustainable because this type of food is consumed by many people in East Java and is a centre for souvenirs for migrants. The production of Sambel Pecel has now begun to spread in other places in East Java, such as the Pasuruan area, especially in the Purwosari sub-district. The entrepreneur of the "rose" pecel sambel in Purwosari is a recipe derived from a family from Blitar. During the production process, several deficiencies were found that did not follow the Good Manufacturing Practice (GMP) standards so that when tested in the health laboratory, they had not yet passed the test. After surveying the production site, there is one process that does not follow the GMP standards in production, namely the peanut grinding process. Therefore, in the community service activities, the team will conceptualise a multi-purpose grinding machine to be used as a nut mill. From the results of the activities that have been carried out, the pecel sambal grinding machine with a tool capacity of 166.67 grams/minute using an electric motor 1 HP as a mover can be used by partners as a tool to grind the pecel sauce easily. With this grinding machine, the product hygiene partner production is maintained and can minimize production costs so that the partner's profit increases.

Keywords : General Purpose Grinding Machine, Food Production, Pecel Sambel, GMP Standards

\section{PENDAHULUAN}

Dalam perkembangan teknologi, terutama pada penerapan teknologi pada produksi pangan perlu memperhatikan aspek keamanan pangan. Pada keamanan pangan perlu dikaitkan dengan adanya bahaya asal pangan saat dikonsumsi oleh konsumen. Bahaya keamanan pangan dapat terjadi disetiap tahapan rantai pangan. Oleh karena itu perlu pengendalian yang cukup disetiap tahapan rantai pangan dengan merumuskan standar 
keamanan pangan setiap tahapan. Standar dalam keamanan pangan disetiap tahapan meliputi, komunikasi interaktif, manajemen sistem, program persyaratan dasar, prinsip HACCP. Tahapan tahapan dalam keamanan pangan dari produsen sampai konsumen perlu diperhatikan, terutama pada tahapan produsen. Produsen merupakan yang memproduksi pangan dari bahan baku sampai menjadi bahan siap saji. Dalam proses produksi perlu diperhatikan beberapa hal, mulai dari kebersihan tempat, kebersihan alat, pengolahan limbah, pengemasan produk sampai pengiriman. Ketentuan -ketentuan tersebut dirumuskan berdasarkan standar SNI ISO 22000:2009 (SNI ISO 22000, 2009). Hal yang terpenting yaitu dalam proses produksi pangan, tingkat higienitas hasil pangan perlu diperhatikan (Adetola \& Oyejide, 2015; Adeyemi, 2008; Andamoyo \& Isroin, 2012).

Alat produksi pangan berbeda dengan alat produksi barang lainnya, makanya perlu suatu pengkajian perancangan dalam alat produksi pangan. Seperti halnya pada produksi pangan industry rumah tangga, seringkali ditemukan kesalahan proses dalam memproduksi pangan. Salah satunya industry rumah tangga sambel pecel di Kecamatan Purwosari Kabupaten Pasuruan.

Pada industry rumah tangga sambel pecel di Kecamatan Purwosari ini ditemukan salah satu kesalahan proses produksinya yaitu proses produksi penggilingan sambel pecel. Pada proses penggilingan tidak sesuai dengan standar GMP (Andamoyo, 2012). Pada penggilingan di tempat umum, mesin giling digunakan untuk penggilingan segala bahan baik itu bahan mentah atau matang dan bahan bersih maupun bahan kotor. Dari proses inilah yang menyebabkan produksi sambel pecel tidak lolos uji E Coli dan Total Coliform. Sedangkan pada proses produksi lainnya sudah mendekati standar GMP. Cara produksi makanan yang baik (CPMB) yaitu pedoman dalam memproduksi makanan dengan mengutamakan dan menjaga mutu dan keamanan agar makanan tersebut layak untuk dikonsumsi (Chandra, 2012; Djiwo, et al., 2018; Hidayati, 2012; Rudiyanto, 2016). Oleh karena itu perlu adanya perancangan ulang mesin penggiling sambel pecel dengan menggunakan penggerak motor listrik.

Dalam proses perancangan mesin teknologi tepat guna, ada beberapa factor yang perlu ditentukan terlebih dahulu menggunakan perhitungan. Perhitungan - perhitungan yang perlu dilakukan seperti, kapasitas mesin, daya motor, besar pully, dimensi mesin, dimensi mata pisau (Sunday dan Ndaliman, 2015; Wibowo, et al., 2018; Wijaya dan Indri, 2016). Dalam perhitungan daya motor bertujuan untuk menentukan kebutuhan motor yang digunakan. Untuk pemilihan menggunakan motor dengan daya yang lebih besar dari daya perhitungan. Hal ini dikarenakan untuk menghindari adanya over heat pada mesin penggerak (Djiwo, et al., 2018). Pada mesin penggiling sambel pecel terdapat beberapa komponen seperti, rangka mesin, tabung penggilingan, mata pisau, saringan, tutup saringan, as mata pisau, bearing, reducer, motor listrik, pully dan V-belt. Perhitungan tersebut menggunakan persamaan - persamaan sebagai berikut (Rudiyanto \& Heru. 2016):

1. Kapasitas mesin

$$
\text { Kapasitas alat }=\frac{\text { Massa Bahan Baku }}{\text { Waktu }}
$$

2. Torsi Mesin

$$
\text { Torsi maksimum }=\frac{5250 \times \mathrm{Hp}}{n}
$$

3. Putaran penggiling

$$
\frac{N_{1}}{N_{2}}=\frac{D_{1}}{D_{2}}
$$

Dari hasil perhitungan yang dilakukan, langkah selanjutnya mendesain mesin serta menentukan jenis bahan dan spesifikasinya. Bahan yang digunakan dalam perancangan mesin penggiling sambel pecel ini, untuk rangka menggunakan besi siku, tabung penggiling 
stainless, mata pisau dan saringan menggunakan bahan stainless. Setiap komponen yang bersentuhan dengan bahan makanan menggunakan bahan logam stainless (Sunday, 2015).

\section{METODE}

\section{Metode Pendekatan}

Dalam menyelesaikan permasalahan dapat digunakan dengan metode pendekatan (Wibowo, et al, 2018). Adapun beberapa solusi yang ditawarkan untuk menyelesaikan permasalahan didalam mitra yaitu:

1. Proses penggilingan sendiri menggunakan mesin grinding serba guna

2. Mendisiplinkan sistem kerja yang mengarah standar good manufacturing practice (GMP).

Untuk mencapai solusi yang ditawarkan diatas tim pengabdian menyusun beberapa metode pendekatan yaitu,

1. Survei keadaan di mitra dan mendiskusikan permasalahan serta solusi yang akan digunakan.

2. Melakukan pelatihan dengan mitra tentang cara pengoperasian alat, keselamatan kerja dan perawatan alat menggunakan sistem on the job training (OJT).

\section{Metode Reverse Engineering}

Pada proses reverse engineering terdapat 3 tahapan yang dilakukan, yaitu (Wijaya \& Indri, 2016) :

A. Disassembly

Proses ini merupakan identifikasi alat yang sudah ada di UKM dengan mencari kekurangan dan kelebihan. Pada tahap ini dilakukan pembongkaran alat, kemudian pengukuran dimensi alat dan jenis bahan yang digunakan.

B. Assembly

Pada proses assembly merupakan perakitan ulang setelah identifikasi alat yang sudah ada. Pada proses ini sudah mendapatkan data - data ukur dimensi alat untuk digunakan sebagai bahan proses bachmarking.

C. Benchmarking

Pada proses benchmarking merupakan tahap akhir, dimana proses ini merupakan rancangan ulang mesin. Dari hasil tahapan sebelumnya didapatkan kelebihan dan kekurangan mesin sehingga dalam proses ini kekurangan yang terdapat di rancang ulang untuk meminimalisir kekurangan.

\section{Desain Mesin Penggiling Sambel Pecel}

Desain mesin penggilingan dapat dilihat pada Gambar 1.

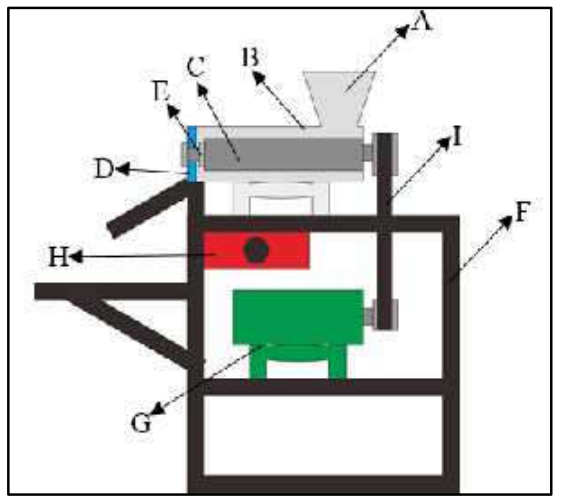

Gambar 1. Desain penggiling sambel pecel 
Keterangan :
A : Chopper
D : Saringan
$\mathrm{G}$ : Motor listrik
$B$ : Tabung penggiling
E : Rangka mesin
$\mathrm{H}:$ Saklar on/off
$\mathrm{C}:$ As penggiling
$\mathrm{F}$ : Mata pisau
I : V-belt

\section{HASIL DAN PEMBAHASAN}

Setelah dilakukan proses reverse engineering dimana ada 3 tahapan yaitu, disassembly, asemby dan bachmarking dilakukan perhitungan - perhitungan untuk proses pembuatan. Sebelum proses pembuatan dilakukan, mendesain terlebih dahulu menggunakan software inventor. Dengan dimensi ukuran yang sudah lengkap, proses selanjutnya adalah pembuatan mesin giling sambel pecel seperti Gambar 2.

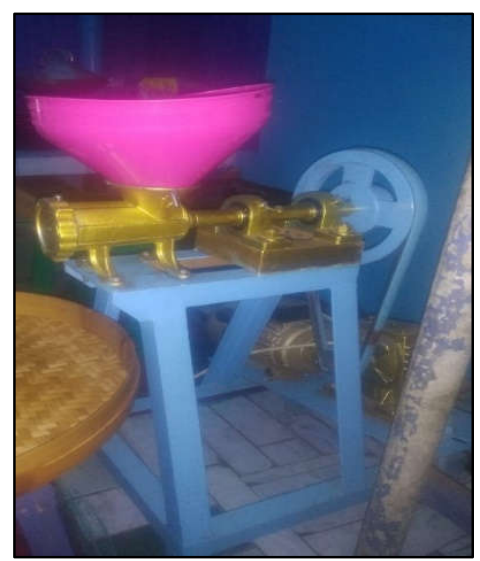

Gambar 2. Mesin penggiling sambel pecel

\section{Komponen - komponen utama mesin penggiling}

\section{Tabung Giling}

Tabung giling merupakan tempat / wadah penggilingan bahan baku sambel pecel. Tabung giling ini memiliki ukuran panjang $35 \mathrm{~cm}$ dan berdiameter $15 \mathrm{~cm}$. bagian atas tabung giling terdapat lubang masuk bahan yang memiliki diameter $10 \mathrm{~cm}$. tabung giling ini menggunakan material stainless steel agar higienitas bahan baku terjaga dan tidak mudah korosi. Bahan baku yang sudah siap digiling dimasukkan melalui bagian atas tabung giling. Kemudian prinsip kerja didalamnya terdapat ulir penggiling untuk menggerakkan bahan baku kearah keluar.

\section{Ulir Penggiling}

Ulir penggiling merupakan komponen didalam tabung giling. Ulir penggiling ini memiliki fungsi sebagai penjalan bahan yang akan digiling ke mata pisau.diameter ulir penggiling ini $14 \mathrm{~cm}$ dan memiliki panjang $35 \mathrm{~cm}$ dengan jarak regangan $25 \mathrm{~mm}$ seperti pada Gambar 3. Bahan ulir penggiling dari stainless steel dengan proses pembentukan ulir menggunakan mesin bubut.

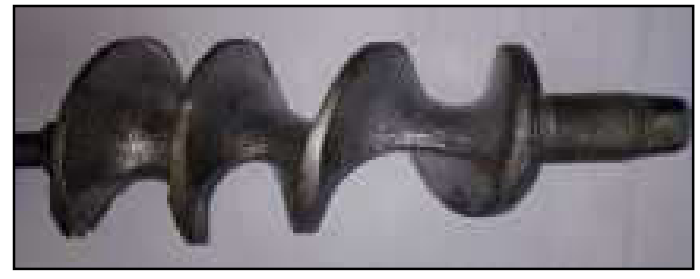

Gambar 3. Ulir penggiling 


\section{Mata Pisau}

Mata pisau merupakan salah satu komponen utama dalam mesin giling sambel pecel. Mata pisau ini berfungsi sebagai pencacah bahan baku. Mata pisau memiliki model palang seperti Gambar 4 dengan setiap ujung palangnya diruncingkan. Mata pisau dibuat menggunakan bahan stainless stell dengan ukuran lingkaran $12,9 \mathrm{~cm}$ serta allowance 0,1 agar dapat berputar bebas didalam tabung berdiameter $15 \mathrm{~cm}$.

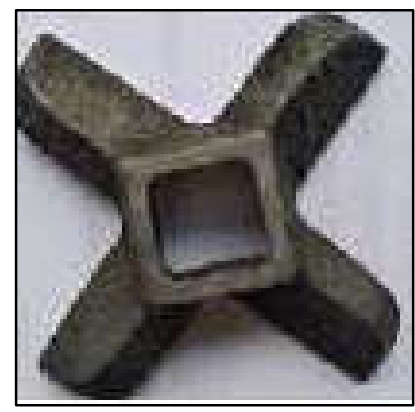

Gambar 4. Mata pisau

\section{Plat Saringan}

Plat saringan berfungsi sebagai penahan bahan baku agar hasil cacahan bahan baku bisa maksimal. Kasar halusnya hasil cacahan tergantung pada diameter plat saringan. Plat saringan terbuat dari bahan stainless steel dengan diameter $15 \mathrm{~cm}$ dan tebal $5 \mathrm{~mm}$ seperti pada Gambar 5. Pada plat saringan mesin giling sambel pecel yang dirancang ini memiliki diameter saringan $2 \mathrm{~mm}$.

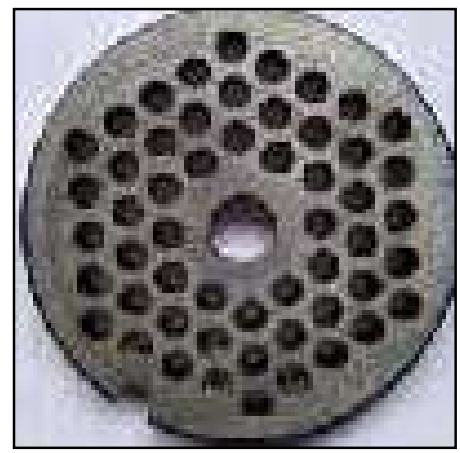

Gambar 5. Plat saringan

\section{Perhitungan - perhitungan mesin penggiling}

Perhitungan dalam perancangan mesin penggiling sambel pecel, meliputi :

\section{Kapasitas Mesin}

Dengan menggunakan persamaan 1 didapatkan hasil perhitungan,

Kapasitas mesin $=\frac{\text { massa bahan }}{\text { waktu }}=\frac{2500}{15}=166,67$ gram $/$ menit

\section{Daya Motor Penggerak}

Daya motor $=\frac{0,7 \times 3,14 \times 120 \times 1440}{60}=0,633 \mathrm{HP}$

Dari perhitungan daya motor yang dibutuhkan $0,633 \mathrm{HP}$, maka dalam perancangan mesin penggiling sambel peccel ini menggunakan daya motor listrik $1 \mathrm{HP}$ agar daya motor lebih kuat dan tidak mudah overheat. 


\section{Torsi Maksimum}

Perhitungan torsi maksimum menggunakan persamaan 2, dimana telah diketahui daya motor $1 \mathrm{HP}$ dan putaran motor 1440 maka didapatkan hasil torsi maksimum.

Torsi maksimum $=\frac{5250 \times \mathrm{Hp}}{\mathrm{n}}=\frac{5250 \times 1}{1440}=3,65 \mathrm{lb} . \mathrm{ft}=4,93 \mathrm{Nm}$

\section{Kecepatan Ulir Penggiling}

Setelah diketahui torsi maksimum langkah selanjutnya menghitung putaran ulir penggiling dan mata pisau dengan menggunkan persamaan 3 .

$$
\begin{aligned}
& \frac{N_{1}}{N_{2}}=\frac{D_{1}}{D_{2}} \\
& \frac{1440}{N_{2}}=\frac{25,4}{5,8} \\
& \mathrm{~N}_{2}=328,82 \mathrm{rpm}
\end{aligned}
$$

\section{Torsi Ulir Penggiling}

Sehingga dapat diketahui bahwa torsi pada ulir penggiling :

$$
\begin{aligned}
& \frac{328,82}{1440}=\frac{t}{4,93} \\
& t=\frac{328,82 \times 4,93}{1440}=1,13 \mathrm{Nm}
\end{aligned}
$$

Setelah didapatkan torsi ulir penggiling, maka dapat diketahui gaya yang dihasilkan ulir penggiling sebesar :

$$
\begin{aligned}
& \mathrm{t}=\mathrm{F} \times \mathrm{r} \\
& \mathrm{F}=\frac{t}{r}=\frac{1,13}{0,12}=9,42 \mathrm{~N}
\end{aligned}
$$

\section{Tahapan Proses Produksi Sambel Pecel}

1. Bahan - bahan ditimbang sesuai ukuran resep

2. Bahan - bahan dicuci terlebih dahulu sampai bersih

3. Bahan digoreng secara terpisah

4. Bahan didinginkan terlebih dahulu

5. Bahan di masukkan kedalam mesin penggiling

6. Bahan dikemas dan siap dipasarkan

\section{DAMPAK DAN MANFAAT}

Dampak maupun manfaat yang diterima oleh mitra yaitu, mitra dapat memproduksi sambel pecel secara mandiri dilakukan di rumah. Dengan memproduksi sendiri secara keseluruhan maka higienitas dapat terjaga. Selain itu pengeluaran biaya produksi dapat berkurang sehingga keuntungan mitra dapat meningkat

\section{KESIMPULAN}

Mesin penggiling sambel pecel dengan kapasitas alat 166,67 gram/menit menggunakan motor listrik $1 \mathrm{HP}$ sebagai penggerak dapat digunakan mitra sebagai alat penggiling sambel pecel dengan mudah. Dengan adanya mesin penggiling ini, produksi mitra higienitas produk terjaga dan dapat meminimalisir biaya produksi sehingga keuntungan mitra meningkat. 


\section{REFERENSI}

Adetola, S. O. and Oyejide, A. J. (2015) 'Development of a Bone Milling Machine With Safety Hollow and Low Risk of Electrical Damage', International Journal of Modern Engineering Research. ISSN 2249-6645. 5(6). 52-59.

Adeyemi, M. B. (2008) 'Mechanical Engineering Design', MEE 513 Federal University of Technology Minna. Nigeria.

Andamoyo, S. dan Isroin L. (2012) 'Personal Hygiene', Yogyakarta: Graha Ilmu.

Chandra, B. (2012) 'Pengantar Kesehatan Lingkungan', Jakarta: ECG.

Djiwo, S., Pohan, G. A. dan Praswanto, D. H. (2018) 'Dryer Segel Botol Plastik Untuk Peningkatan Kwalitas Kemasan Botol Vitamin Unggas Di Kecamatan Purwosari Kabupaten Pasuruan', Jurnal Aplikasi dan Inovasi IPTEKS SOLIDITAS. 1(2). 84-89.

Hidayati, D. (2012) 'Penerapan Good Manufacturing Practices di Industri Rajungan PT. Kelola Mina Laut', Jurnal Fakultas Pertanian. Universitas Trunojoyo.

Rudiyanto, H. (2016) 'Kajian Good Manufacturing Practices (GMP) dan Kualitas Mutu Pada Wingko Berdasarkan SNI-01-4311-1996', Departemen Kesehatan Lingkungan. Universitas Airlangga Indonesia.

Sunday, B. dan Ndaliman, M. B. (2015) 'Design of a Manual and Motorized Meet Grinding Machine', International Journal of Engineering Trends and Technology. ISSN 22315381 Vol. 21(2).

SNI ISO 22000 (2009). 'Food Safety Management System - Requirements for Any Organization in the Food Chain', Badan Standarisasi Nasional.

Wibowo, N., Setiani, B. Etza, dan Hintono, A. (2018) 'Karakteristik Hedonik Sambel Pecel Hasil Substitusi Kacang Tanah (Arachis Hypogaea) dengan Kacang Hijau (Vigna Radiata L.)', Jurnal Teknologi Pangan. ISSN 2597-9892. 2(1). 46-49.

Wijaya, N. dan Indri, P. (2016) 'Peningkatan Efisiensi dan Kapasitas Produksi Pada Proses Pengolahan Sambel Pecel, Keripik Tempe dan Keripik Singkong', Jurnal Teknologi Pangan.7(3). 57-62. 